\title{
On Gonads Development And Differentiation During Triatoma Infestans (Klug1896) [Hemiptera, Heteroptera] Embryo-genesis
}

Dr. Marta I. Mariano* **; Lic. Cecilia I. Ibáñez*; and Dr. Juan Pablo Bozzini*

*A.N.L.I.S. "Dr. Carlos G. Malbrán” Ave. Velez-Sarsfield 563 (1281) Buenos Aires; República Argentina.

**Research Career Member, Consejo Nacional de Investigaciones.

Different species of hemiptera heteroptera (reduvidae) has been described as vectors of Trypanosoma cruzi, "Cruzi-like" trypanosomes, Trypanosoma rangeli, Blastochritidiae, and some other flagellates regarded as possible infectious agents of human and domestic animals parasitosis. South American trypanosomiasis or "Chagas Disease" has been described from Texas to Patagonia according to the papers published during the last fifty years.

The interest on the biology of such hemiptera has been increased since the fundamental paper by E. Del Ponte (1921-1922) which cover different species pertaining to the genuses Triatoma, Pastrongilus, Rhodnius, etc. to mention those still considered true generic names in the international nomenclature. All Reduvidae bugs are insects with incomplete metamorphosis, hemimetabola that comprises at least five stages. Most of the description of gonads development since Del Ponte publication agree for Triatoma that defined reproductive organs appear from the third (or fourth) instars on, to complete maturation at the adult stage (wing bearing insects).

Our microscopic studies and 3-D reconstructions of early nymphs instars and embryos, demonstrate the presence of differentiated tissue that will develop to conform gonads during early days of egg development (depending on the incubation temperature), either after "in-vitro" reared from ova insects as well as eggs derived form wild females collected from primitive houses or sheep and goat yards.

Although most embryo development descriptions in hemiptera are rather discordant and incomplete, the careful studies of serial sections of developmental eggs and nymphs, embedded in poly-bed araldite and mounted in the same resin under phase contrast microscope, gave improved photo-micrographs that allow us a better understanding on organs development prior to egg hatching and beyond meant for these insects throwing away previous misapprehensions, confirming an early differentiation of male and female gonads.. 
Characterization of cells ultra structure by TEM corroborate the time sequence follow-up of this important specialized tissue. Thus it is also shown the important cell structure modifications that take place in the gonads during the nymph stages to the last molt, when the insects reach maturity.

An important conclusion coming up from this research is that for Triatoma infestans gonads are morphological complete (although immature) in both sexes prior to larva egg hatching, and that differentiated cell type that will give rise to these organs is present at a former cleavage time, perhaps at the same time that the head start to take place.

[1] Del Ponte E., Revista Inst. Bact. Dep. Nac. Higiene (1921) 54 - 73.

[2] Del Ponte E., Ibidem (1922) 17 - 31.

[3] Lent H. and Wygoezinsky P., Bull. Amer. Mus. Nat. Hist (1979) 127 - 520.

[4] Mariano M., Ibañez C. And Bozzini J.P., Biocell (1997) 123 - 152.

[5] Goncales T., Lent H. And Riveiro de Almeida, Mem. Inst. Oswaldo Cruz (1987) 543-550.

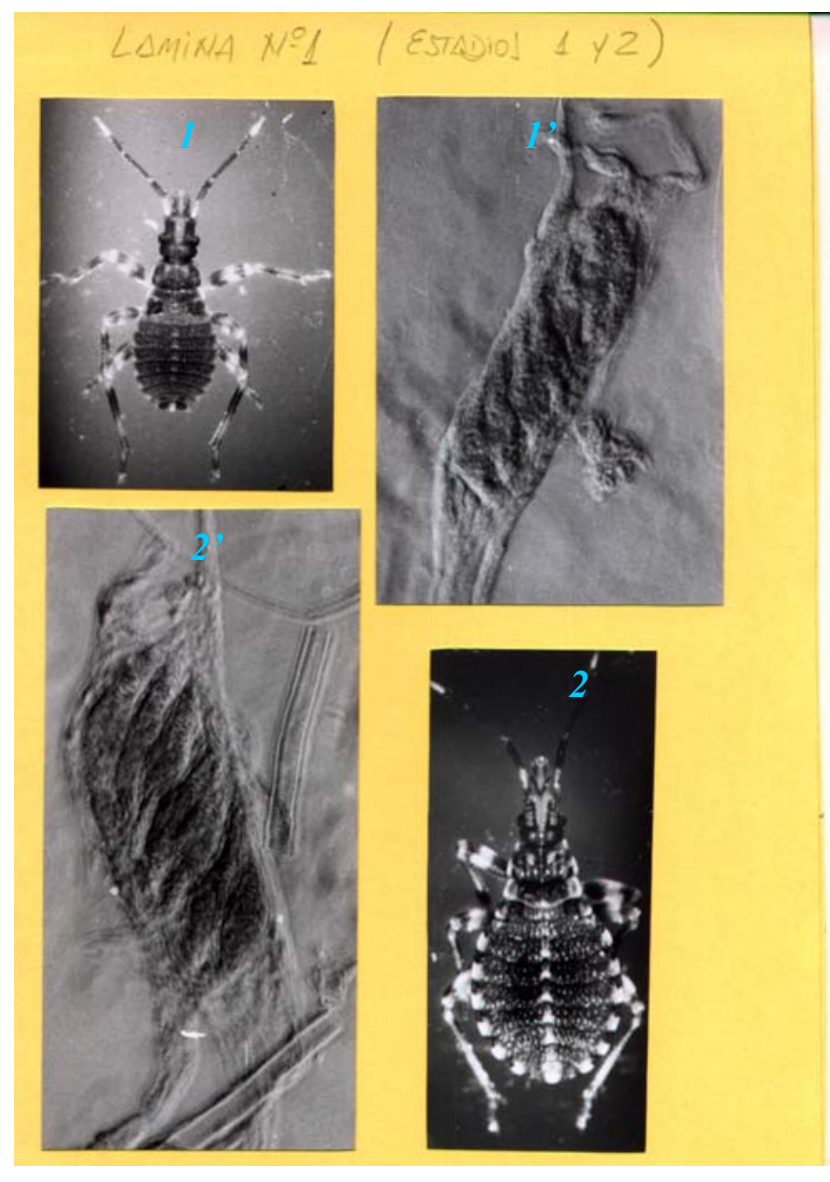

1 and 1': Triatoma infestans first instar larva few hours after hatching and its female gonads.

2 and 2': the same pictures but for the second instars after the first molt.

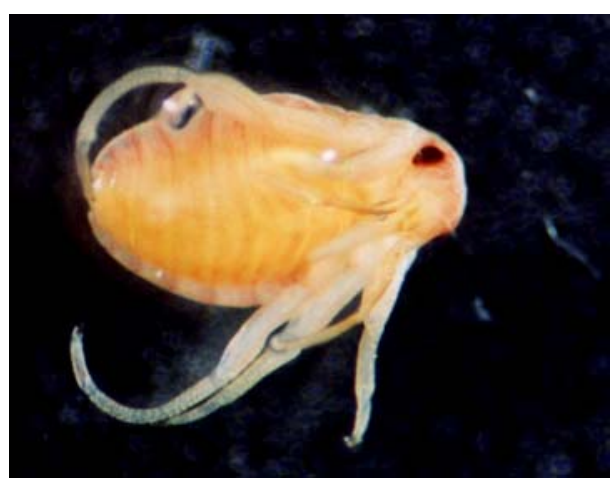

Triatoma infestans embryo from eight to nine days of incubation taken out from corionic envelope

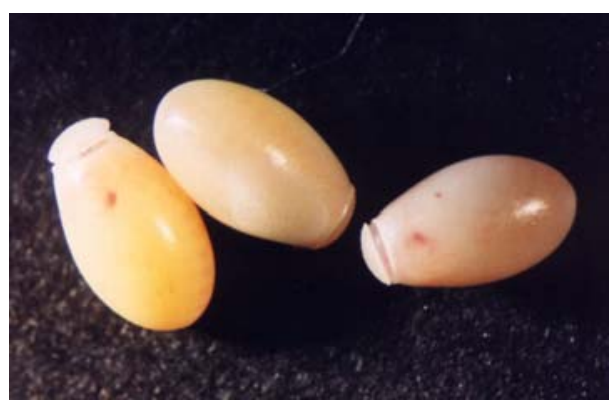

Triatoma infestans eggs few hours (approximately three to four) before hatching. 
https://doi.org/10.1017/S1431927603446990 Published online by Cambridge University Press 